\title{
Performance Tests for an All-welded Plate Heat Exchanger Liang Huang ${ }^{1, a}$, Bingcheng Liu ${ }^{1, b}$ and Qingling $\mathrm{Li}^{1, \mathrm{C}}$ \\ ${ }^{1}$ College of Electromechanical Engineering, Qingdao University of Science and Technology, Qingdao 266061, China. \\ ahuangliang618@163.com, bbingchengl@163.com, eduqust@163.com
}

Keywords: All-welded plate heat exchanger, heat transfer, pressure drop.

\begin{abstract}
Heat transfer and pressure drop in an all-welded plate heat exchanger with ripples have been experimentally investigated in this paper. The ripples were corrugated by the way of special machine. The heat transfer coefficient and pressure drop was experimented, and also calculated by the wall temperature method. The flow of water inside the plate heat exchanger was arranged as a single-pass and countercurrent. The hot water and cold water inlet temperatures were maintained at around $50^{\circ} \mathrm{C}$ and $35^{\circ} \mathrm{C}$, respectively, while the hot oil and cold water inlet temperatures were got at about $40^{\circ} \mathrm{C}$ and $35^{\circ} \mathrm{C}$, respectively. It indicated that the overall heat transfer coefficient calculated by wall temperature method fitted the actual value.
\end{abstract}

\section{Nomenclature}

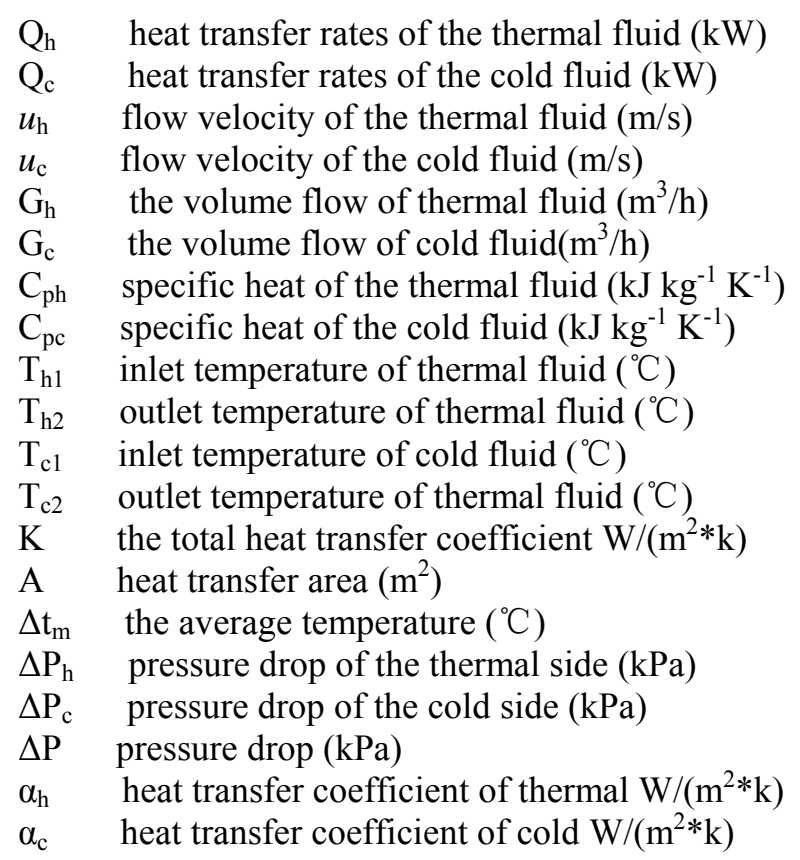

\section{Introduction}

Plate heat exchanger as a thermal element with superior heat transfer performance, is widely used in petroleum industry, chemical industry, power industry, mechanical ship industry and other industries. It has great vital significance to research on heat transfer enhancement technology. The plate heat exchangers have the advantages of high transfer efficiency, flexibility, and ease of maintenance and cleaning. But the performance of plate heat exchanger is determined by many factors such as corrugation inclination angle, the flow mechanism of fluid, geometrical parameters, fluid distribution and so on.

In order to obtain high efficiency, low resistance of the plate heat exchanger, many scholars around the word made a series of studies on the plate heat exchanger. Corrugated inclination angle $\beta$ of chevron plate heat exchanger was first studied by W. W. Focke [1] who changed the angle and other parameters to improve heat transfer efficiency. Muley and Manglik [2] further studied the 
different forms of the plate heat exchanger, heat transfer coefficient correlation was amended and area expansion coefficient was also introduced. Reinhard Wurfd [3] studied the steam condenses experiment with different structures of plate heat exchanger, also studied the effect of corrugation inclination angle $\beta$ for heat transfer and pressure drop in two-phase flow plate heat exchanger. $Z$. Vlahostergios [4] researched the effect of turbulence intensity on the pressure drop in elliptical tube heat exchanger, the results suggested that increased turbulence intensity lead to decreased pressure drop of the heat exchanger. A A Gholami [5] studied three different baffles and baseline impact on heat transfer and pressure drop in fin tube heat exchanger, the result showed a rectangular wavy fin can significantly improve the heat transfer performance and reduce the pressure drop. The heat transfer and pressure drop was researched by visualization technology under conditions of two-phase coexistence between air and water in the study of Asano [6]. The geometric parameters of plate were also studied as the factors that influence the heat transfer and pressure drop of plate heat exchanger. Bahadır Dogan [7] compared the heat exchanger performance between double and multi-row fin heat exchanger by studying the exchanger side of air, studies showed that in quasi-steady state, the double fin heat exchanger with higher thermal performance and efficiency, and the friction factor is also high. Muley [8] noted the uneven distribution of the fluid in the plate heat exchanger was a major factor that affected the performance of the plate heat exchanger.

The emergence of various plate heat exchangers [9-12] greatly broadened the application field of plate heat exchanger. The plate structure of all welded plate reactor was a complex network port, which can effectively promote the fluid turbulence. In this paper, the heat transfer and pressure drop of an all-welded plate heat exchanger was investigated.

\section{Experimental}

\section{Heat exchanger}

Fig. 1 showed that the schematic diagram and entities picture of the test all-welded plate heat exchanger. The all-welded plate heat exchanger comprised of a series of plates welded together to form cassettes which were stacked one on top of another to provide channels for flowing fluids to exchange heat. Two sheet frames with inlet, two sheet frames with outlet, a top cover and a bottom cover with foundation enclosed the stacked cassettes. The all-welded plate heat exchanger, with the heat transfer area of $4.5 \mathrm{~m}^{2}$, contained 11 plates, where provided 5 channels for thermal fluids and 5 channels for cold fluids. The corrugation depth and corrugation pitch were $4 \mathrm{~mm}$ and $14 \mathrm{~mm}$, respectively, and the outer frame of the heat exchanger was $1388 \times 496 \mathrm{~mm}$.
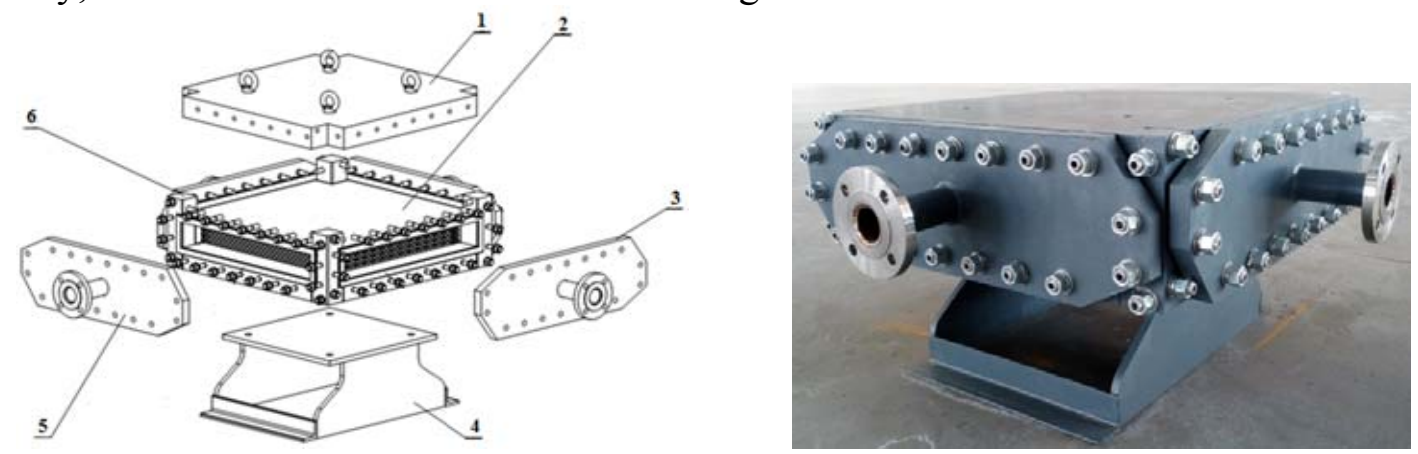

1 top cover; 2 stacked cassettes; 3 sheet frame with inlet;

4 bottom cover with foundation; 5 sheet frame with outlet; 6 stand column

Fig. 1 Schematic diagram and entities picture of the test all-welded plate heat exchanger

\section{Test process.}

The heat transfer performance and pressure drop were investigated with water-water and water-thermal oil (LONTHERM-60) as heat transfer fluids, respectively. The temperature was measured by Pt100 thermocouples, and the flow rate of fluids was measured by turbine flow-meters. Cold and thermal heat transfer fluids were flowed in full countercurrent type. 
Data processing formula.

The average heat transfer rate

$$
\begin{aligned}
& Q=\frac{Q_{c}+Q_{h}}{2} \\
& \boldsymbol{Q}_{\boldsymbol{h}}=\boldsymbol{G}_{\boldsymbol{h}} \cdot \boldsymbol{\rho}_{\boldsymbol{h}} \cdot \boldsymbol{C}_{\boldsymbol{p h}} \cdot\left(\boldsymbol{t}_{\left.\boldsymbol{h} \boldsymbol{h}^{-} \boldsymbol{t}_{\boldsymbol{h} 2}\right)}\right. \\
& \boldsymbol{Q}_{\boldsymbol{c}}=\boldsymbol{G}_{\boldsymbol{c}} \cdot \boldsymbol{\rho}_{\boldsymbol{c}} \cdot \boldsymbol{C}_{\boldsymbol{p} \boldsymbol{c}} \cdot\left(\boldsymbol{t}_{\boldsymbol{c} 2}-\boldsymbol{t}_{\boldsymbol{c} 1}\right) \\
& K_{1}=\frac{Q_{c}}{A \times \Delta t_{m}}
\end{aligned}
$$

Wall temperature method to calculate the overall heat transfer coefficient

First, the heat transfer coefficient of cold side and the thermal side were calculated, and then use the formula (9) to calculate the overall heat transfer coefficient.

$$
\begin{aligned}
& \boldsymbol{q}=\boldsymbol{\alpha}_{h}\left(\boldsymbol{t}_{m h}-\boldsymbol{t}_{w h}\right) \\
& \boldsymbol{q}=\frac{\lambda\left(\boldsymbol{t}_{w h}-\boldsymbol{t}_{w c}\right)}{\boldsymbol{\delta}} \\
& \boldsymbol{\alpha}_{h}=\frac{\boldsymbol{q}}{\boldsymbol{t}_{m h}-\boldsymbol{t}_{w h}} \\
& \boldsymbol{\alpha}_{c}=\frac{\boldsymbol{q}}{\boldsymbol{t}_{w c}-\boldsymbol{t}_{m c}} \\
& \frac{1}{K_{2}}=\frac{1}{\alpha_{c}}+\frac{1}{\alpha_{h}}
\end{aligned}
$$

\section{Results and discussion}

The study of heat transfer coefficient and pressure drop in water-to-water

Table 1 showed that the experimental results at constant flow rate of thermal and cold fluid in water-to-water. From Table 1, the heat transfer coefficient that calculated by the wall temperature method and experimentally measured was compared, the relative error of heat transfer coefficient was also calculated. The date showed that the use of wall temperature method to calculate heat transfer coefficient was basically consistent with the actual test.

Table 1 Experimental results at constant flow rate of thermal and cold fluid in water-to-water

\begin{tabular}{ccccccccccccc}
\hline$N$ & $\begin{array}{c}u_{\mathrm{h}} \\
\mathrm{m} / \mathrm{s}\end{array}$ & $\begin{array}{c}\mathrm{T}_{\mathrm{h} 1} \\
{ }^{\circ} \mathrm{C}\end{array}$ & $\begin{array}{c}\mathrm{T}_{\mathrm{c} 1} \\
{ }^{\circ} \mathrm{C}\end{array}$ & $\begin{array}{c}\mathrm{T}_{\mathrm{h} 2} \\
{ }^{\circ} \mathrm{C}\end{array}$ & $\begin{array}{c}\mathrm{T}_{\mathrm{c} 2} \\
{ }^{\circ} \mathrm{C}\end{array}$ & $\begin{array}{c}\Delta \mathrm{P}_{\mathrm{h}} \\
\mathrm{kPa}\end{array}$ & $\begin{array}{c}\Delta \mathrm{P}_{\mathrm{c}} \\
\mathrm{kPa}\end{array}$ & $\begin{array}{c}\mathrm{Q}_{\mathrm{h}} \\
\mathrm{kW}\end{array}$ & $\begin{array}{c}\mathrm{Q}_{\mathrm{c}} \\
\mathrm{kW}\end{array}$ & $\begin{array}{c}\mathrm{K}_{1} \\
\mathrm{~W} /\left(\mathrm{m}^{2} * \mathrm{k}\right)\end{array}$ & $\begin{array}{c}\mathrm{K}_{2} \\
\mathrm{~W} /\left(\mathrm{m}^{2} * \mathrm{k}\right)\end{array}$ & $\begin{array}{c}\text { error } \\
10^{-3}\end{array}$ \\
\hline 1 & 0.2 & 43.76 & 13.04 & 30.11 & 26.81 & 3.65 & 6.35 & 102.23 & 103.13 & 1341.39 & 1341.43 & 0.7455 \\
2 & 0.3 & 48.63 & 29.50 & 39.71 & 38.47 & 6.64 & 8.44 & 100.73 & 100.50 & 2194.77 & 2195.28 & 0.4556 \\
3 & 0.4 & 44.05 & 31.51 & 37.92 & 37.90 & 13.70 & 10.37 & 91.44 & 95.34 & 3305.45 & 3304.67 & 0.3025 \\
4 & 0.5 & 50.81 & 33.85 & 42.07 & 42.49 & 22.59 & 15.33 & 163.22 & 161.71 & 4366.70 & 4365.58 & 0.2290 \\
5 & 0.6 & 50.21 & 34.87 & 42.11 & 43.09 & 31.67 & 19.45 & 181.11 & 184.21 & 5650.55 & 5653.36 & 0.1770 \\
6 & 0.7 & 49.71 & 35.31 & 41.86 & 43.21 & 42.65 & 24.39 & 204.66 & 205.74 & 6988.81 & 6988.50 & 0.1431 \\
7 & 0.8 & 49.99 & 35.79 & 42.03 & 43.83 & 57.58 & 31.40 & 236.80 & 240.05 & 8537.43 & 8545.70 & 0.1171 \\
8 & 0.9 & 49.60 & 36.15 & 41.91 & 43.86 & 67.64 & 37.32 & 249.74 & 250.70 & 9674.60 & 9670.34 & 0.1034 \\
9 & 0.8 & 50.33 & 36.58 & 42.69 & 44.35 & 56.63 & 31.34 & 227.88 & 231.23 & 8437.69 & 8438.75 & 0.1185 \\
10 & 0.7 & 50.94 & 36.83 & 43.25 & 44.50 & 42.65 & 24.41 & 200.79 & 200.88 & 6946.72 & 6940.90 & 0.1440 \\
11 & 0.6 & 50.27 & 36.79 & 43.10 & 43.90 & 32.67 & 20.32 & 161.59 & 159.66 & 5635.10 & 5630.04 & 0.1775 \\
12 & 0.5 & 50.17 & 36.68 & 43.31 & 43.49 & 22.59 & 14.31 & 128.11 & 127.55 & 4268.64 & 4268.47 & 0.2343 \\
13 & 0.4 & 52.26 & 36.48 & 44.66 & 43.98 & 13.70 & 9.35 & 113.94 & 111.00 & 3037.45 & 3036.86 & 0.3292 \\
14 & 0.3 & 50.21 & 36.60 & 43.97 & 42.81 & 6.63 & 8.40 & 70.08 & 69.94 & 2107.02 & 2106.67 & 0.4746 \\
15 & 0.2 & 52.41 & 36.48 & 45.60 & 43.03 & 3.66 & 6.32 & 51.41 & 49.47 & 1211.95 & 1211.77 & 0.8251 \\
\hline
\end{tabular}

The change of heat transfer coefficient with flow rate was shown in Fig. 2, which showed that the heat transfer coefficient increased with the increasing flow rate. With the increasing flow rate, 
the turbulent fluid level increased. Dot dither and mixing occurred, so the heat transfer coefficient increased. The change of pressure drop with the flow rate was shown in Fig. 3. With the increased of flow rate, a corresponding increase in the frictional resistance, the pressure drop also increased.

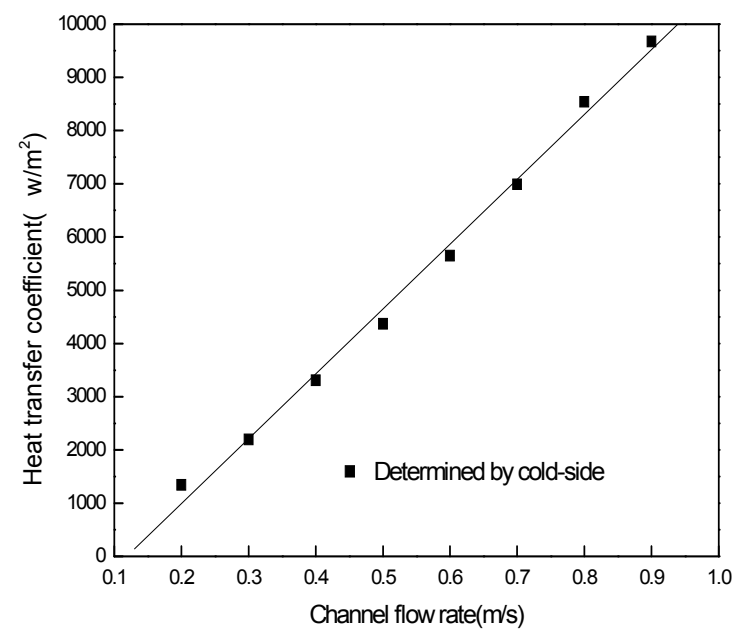

Fig. 2 Test relation curves of heat transfer coefficient and the velocity (water-to-water)

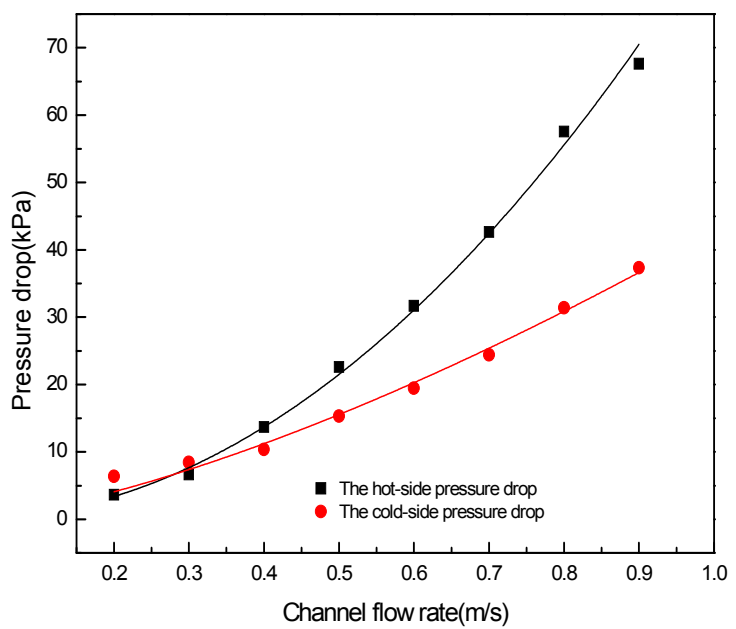

Fig. 3 Test relation curve of pressure drop and the velocity (water-to-water)

\section{The study of heat transfer coefficient and pressure drop in oil-to-water}

Table 2 showed that the experimental results at constant flow rate of cold fluid in oil-water. From Table 2, the overall heat transfer coefficient that calculated by the wall temperature method and experimentally measured was compared, the error was also calculated. The result showed that the calculated heat transfer coefficient was basically consistent with the actual test value.

The change of heat transfer coefficient with velocity can be shown in Fig. 4, the heat transfer coefficient increased with the increased of channel flow rate. Heat transfer resistance is mainly concentrated in the boundary layer, the temperature boundary layer thinning with the increase of flow velocity, heat transfer rate increased, heat transfer coefficient also increased. The change of pressure drop with the flow rate was shown in Fig. 5. With the increasing flow rate, the pressure drop increased. 


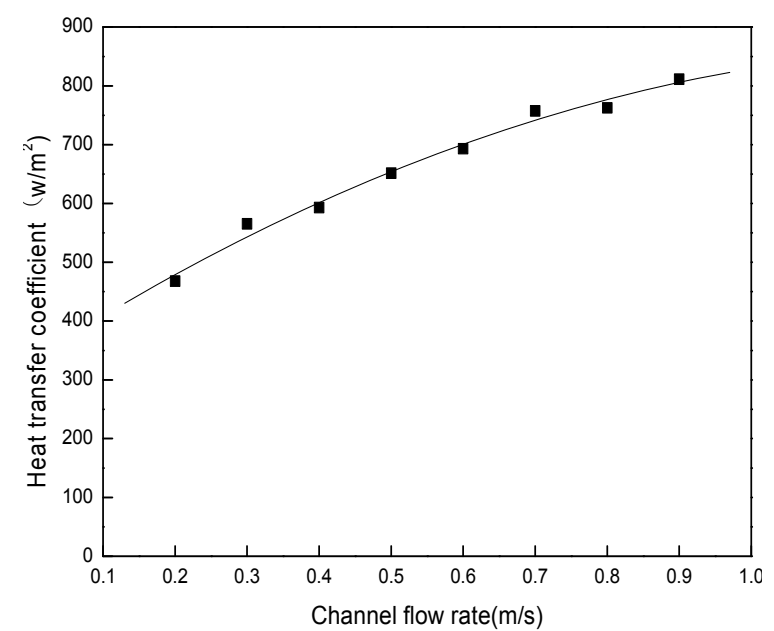

Fig. 4 The test curve of heat transfer coefficient and the velocity (oil-to-water)

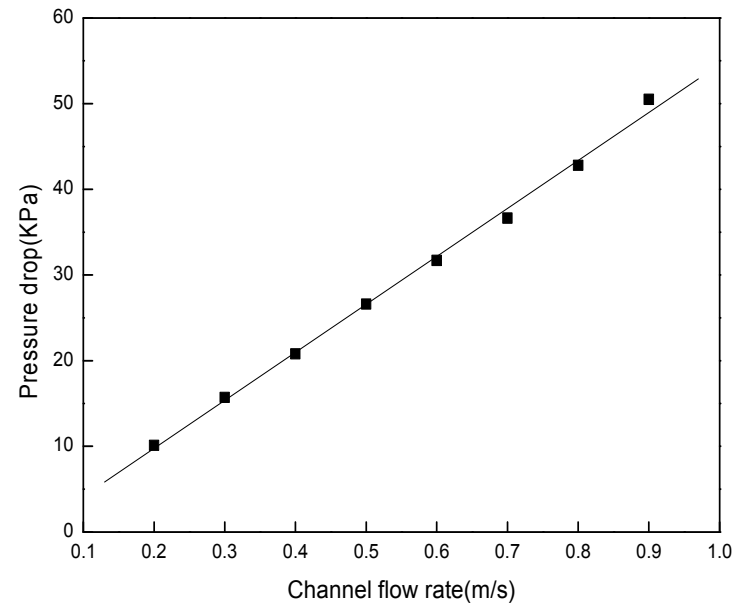

Fig. 5 The test curve of pressure drop and the velocity (oil-to-water)

Table 2 Experimental results at constant flow rate of cold fluid in oil-water

\begin{tabular}{|c|c|c|c|c|c|c|c|c|c|c|c|c|c|}
\hline$N$ & $\begin{array}{l}u_{\mathrm{h}} \\
\mathrm{m} / \mathrm{s}\end{array}$ & $\begin{array}{c}u_{\mathrm{c}} \\
\mathrm{m} / \mathrm{s}\end{array}$ & $\begin{array}{l}\mathrm{T}_{\mathrm{h} 1} \\
{ }^{\circ} \mathrm{C}\end{array}$ & $\begin{array}{l}\mathrm{T}_{\mathrm{cl}} \\
{ }^{\circ} \mathrm{C}\end{array}$ & $\begin{array}{l}\mathrm{T}_{\mathrm{h} 2} \\
{ }^{\circ} \mathrm{C}\end{array}$ & $\begin{array}{l}\mathrm{T}_{\mathrm{c} 2} \\
{ }^{\circ} \mathrm{C}\end{array}$ & $\begin{array}{l}\Delta \mathrm{P}_{\mathrm{h}} \\
\mathrm{kPa}\end{array}$ & $\begin{array}{l}\Delta \mathrm{P}_{\mathrm{c}} \\
\mathrm{kPa}\end{array}$ & $\begin{array}{r}\mathrm{Qh}_{\mathrm{h}} \\
\mathrm{kW}\end{array}$ & $\begin{array}{r}\mathrm{Q}_{\mathrm{c}} \\
\mathrm{kW}\end{array}$ & $\begin{array}{c}\mathrm{K}_{1} \\
\mathrm{~W} /\left(\mathrm{m}^{2} * \mathrm{k}\right)\end{array}$ & $\begin{array}{c}\mathrm{K}_{2} \\
\mathrm{~W} /\left(\mathrm{m}^{2} * \mathrm{k}\right. \\
)\end{array}$ & Error \\
\hline 1 & 0.2 & 0.5 & 46.71 & 33.78 & 40.50 & 34.82 & 10.13 & 15.35 & 19.49 & 18.68 & 468.05 & 455.79 & 2.6902 \\
\hline 2 & 0.3 & 0.5 & 41.68 & 33.89 & 38.43 & 34.65 & 15.72 & 15.35 & 14.22 & 14.75 & 565.27 & 556.42 & 1.5906 \\
\hline 3 & 0.4 & 0.5 & 41.56 & 33.85 & 38.96 & 34.70 & 20.81 & 15.35 & 15.99 & 15.75 & 593.12 & 589.25 & 0.6566 \\
\hline 4 & 0.5 & 0.5 & 41.50 & 33.67 & 39.15 & 34.66 & 26.62 & 15.35 & 18.41 & 17.57 & 651.39 & 648.99 & 0.3698 \\
\hline 5 & 0.6 & 0.5 & 41.76 & 33.49 & 39.55 & 34.60 & 31.7 & 15.35 & 20.80 & 20.37 & 693.09 & 692.05 & 0.1504 \\
\hline 6 & 0.7 & 0.5 & 41.55 & 33.24 & 39.37 & 34.42 & 36.63 & 15.35 & 22.07 & 23.06 & 757.55 & 756.33 & 0.1618 \\
\hline 7 & 0.8 & 0.5 & 41.97 & 32.73 & 39.90 & 34.13 & 42.81 & 15.35 & 26.15 & 25.31 & 762.52 & 761.86 & 0.0863 \\
\hline 8 & 0.9 & 0.5 & 41.64 & 33.89 & 39.88 & 35.13 & 50.5 & 15.35 & 23.23 & 22.36 & 811.41 & 810.49 & 0.1136 \\
\hline
\end{tabular}

\section{Conclusions}

Heat transfer and pressure drop in an all-welded plate heat exchanger with ripples have been experimentally investigated in this paper. The ripples were corrugated by the way of special machine. The heat transfer coefficient and pressure drop was experimented, and also calculated by the wall temperature method. The overall heat transfer coefficient calculated by wall temperature method fitted the actual value.

\section{Acknowledgments}

The authors would like to thank Xumei Tao, Guowei Wang and Lijun Yu for useful discussions and helps. 


\section{References}

[1]. W W Focke, J Zachariades, I Olivier. The effect of the corrugation inclination angle on the thermohydraulic performance of plate heat exchangers. Heat Mass Transfer, Vol. 28 (1985) No. 8, p. 1469-1479.

[2]. A Muley,R M Manglik. Experimental study of turbulent flow transfer and pressure drop in a plate heat exchanger with Chevron plates. Journal of Heat Transfer, Vol. 121 (1999) No. 1, p. $110-117$

[3]. R Würfel, N Ostrowski. Experimental investigations of heat transfer and pressure drop during the condensation process within plate heat exchangers of the herringbone-type. International Journal of Thermal Sciences, Vol. 43 (2004) No. 1, p. 59-68.

[4]. Z Vlahostergios, D Missirlis, M Flouros, et al. Effect of turbulence intensity on the pressure drop and heat transfer in a staggered tube bundle heat exchanger. Experimental Thermal and Fluid Science, Vol. 60 (2015), p. 75-82.

[5]. A A Gholami, M A Wahid, H A Mohammed. Heat transfer enhancement and pressure drop for fin-and-tube compact heat exchangers with wavy rectangular winglet-type vortex generators. International Communications in Heat and Mass Transfer, Vol. 54 (2014) No. 5, p. 132-140.

[6]. H Asano, N Takenaka, T Fuji, et al. Visualization and void fraction measurement of gas-liquid two-phase flow in plate heat exchanger. Applied Radiation and Isotopes, Vol. 61 (2014) No. 4, p. 707-713.

[7]. B Dogana, Ö Altuna, N Ugurlubileka, et al. An experimental comparison of two multi-1 louvered fin heat exchangers with different numbers of fin rows. Applied Thermal Engineering, Vol. 91 (2015), p. 270-278.

[8]. B P Rao, P K Kumar, S K Das. Effect of flow distribution to the channels on the thermal performance of a plate heat exchanger. Chemical Engineering and Processing, Vol. 41 (2002) No. 1, p. 49-58.

[9]. E Lee, H Kang, Y Kim. Flow boiling heat transfer and pressure drop of water in a plate heatexchanger with corrugated channels at low mass flux conditions. International Journal of Heat and Mass Transfer, Vol. 77 (2014) No. 4, p. 37-45.

[10]. H S Dizaji, S Jafarmadar, F Mobadersani. Experimental studies on heat transfer and pressure drop characteristics for new arrangements of corrugated tubes in a double pipe heat exchanger. International Journal of Thermal Sciences, Vol. 96 (2015), p. 211-220.

[11]. Z W Ma, P Zhang. Pressure drop and heat transfer characteristics of clathrate hydrate slurry in a plate heat exchanger. International Journal of Refrigeration, Vol. 34 (2011) No. 3, p. 796-806.

[12]. K Nilpueng, S Wongwises. Experimental study of single-phase heat transfer and pressure drop inside a plate heat exchanger with a rough surface. Experimental Thermal and Fluid Science, Vol. 68 (2015), p. 268-275. 